\title{
VIRTUAL TOUR AS ONE OF THE MODERN METHODS OF VISUALIZATION ENVIRONMENT BY THE EXAMPLE OF THE UNIVERSITY CAMPUS
}

\author{
O. Yanchuk ${ }^{1}$, O. Holivenkova ${ }^{2}$, V. Vasylyshyna ${ }^{3}$, R. Shulgan ${ }^{4}$
}

DOI: http://doi.org/10.15350/L_26/8/21

\section{Abstract}

The article discusses the main advantages of the virtual tour. Principles of construction the virtual tour by the example of the campus of National University of Water and Environmental Engineering in software Kolor Panotour Pro. Offered the opportunity to views the university campus by using modern means of technology.

Keywords: virtual tour, panorama, multimedia technologies, hotspots.

На сегодняшний день очень популярны разные виды туризма. Хочется побывать во многих странах, изведать их укромные исторические места, заглянуть туда, где не ступала нога человека. В современных условиях это сделать довольно-таки легко. Сегодня очень популярны виртуальные туры, которые благодаря своим значительным возможностям и объективному отражению виртуальной реальности представляют интерес как в туристической отрасли, так и в научной, с целью изучения, исследования и ознакомления с различными типами объектов и не только [9]. Виртуальные туры применяются для осмотра многокомпонентных объектов культурного наследия $[5,10]$, общественных и учебных заведений [4], туристических объектов [7], в рекламных целях [1] и т.д. Приложение Google Street View позволяет виртуально «прогуляться» по улицам многих городов и даже «зайти» в некоторые помещения [8].

Сфера применения сферических 3D-панорам и виртуальных туров очень широка. Сферические панорамы, привлекающее внимание и вызывающие интерес практически любого человека, найдут свое место во многих областях современной жизни. 3D-туры дают возможность совершить виртуальную экскурсию по еще не знакомому городу, посетить известные достопримечательности и места (в которые возможно сложно попасть или утомительно добираться в "штатном" режиме). Виртуальные туры также помогут совершить предварительные экскурсии, спланировать маршрут

${ }^{1}$ Oleksandr Yanchuk, Candidate of Technical Sciences, Associate Professor, National University of Water and Environmental Engineering, Ukraine.

${ }^{2}$ Olena Holivenkova, student, National University of Water and Environmental Engineering, Ukraine.

${ }^{3}$ Viktoria Vasylyshyna, student, National University of Water and Environmental Engineering, Ukraine.

${ }^{4}$ Roman Shulgan, Candidate of Technical Sciences, Associate Professor, National University of Water and Environmental Engineering, Ukraine. 
реального путешествия с целью посетить самые интересные и важные места за максимально короткий промежуток времени. Ими могут быть оснащены информационные центры и сайты городов.

Виртуальный тур - это некая комбинация панорамных фотографий (сферических или цилиндрических). В основе сферической панорамы лежит собранное из нескольких отдельных кадров изображение в сферической или кубической проекции. Их характерной чертой является максимально возможный угол обзора пространства (360×180 градусов). Каждый кадр для панорамной фотографии делается по технологии HDR (High Dynamic Range) - высокого динамического диапазона. Т.е. каждый кадр получается путем совмещения нескольких кадров отснятых с разным значением экспозиции, что в конечном итоге делает панораму более красочной и реалистичной [2]. При этом переход от одной панорамы к другой осуществляется через активные зоны (их называют точками привязки - хотспоты), размещаемые непосредственно на изображениях, а также с учетом плана тура. Хотспот - это изображение, текст или область панорамы, который представляет собой ссылку. При наведении курсора на горячую точку всплывает подсказка, а нажатие активирует загрузку соответствующей 3D-панорамы или открывает всплывающее окно. Горячих точек на одной панораме может быть несколько, они логически соответствуют направлению движения, которое мы используем в реальности [12].

Виртуальные туры имеют и преимущества, и недостатки в их использовании $[7,8,9]$. К преимуществам отнесем:

1. Эффект присутствия, интерактивность - виртуальная панорама позволяет рассмотреть окружающее пространство, масштабировать его, рассмотреть под нужным углом; почувствовать реальность пребывания в исследуемых местах, путешествия ими. Возможность использования дополнительных гаджетов виртуальной реальности.

2. Информативность - возможность получить исчерпывающую дополнительную информацию о любом месте, территории, объекте культурного наследия; просмотреть не только графическую информацию, но и ознакомиться с аудио или видео сопровождением, что может заменить экскурсовода.

3. Универсальность и простота - тур можно разместить на любой интернет странице и его использование не требует специальных навыков и программного обеспечения.

4. Экономия - экономия времени и средств, если нет возможности осуществить реальное путешествие.

5. Сохранение окружающей среды - благодаря виртуальным турам сохраняется чистота и сохранность древних памятников истории, археологии и окружающей среды.

6. Использование в коммерческих целях - осмотр отелей, товаров в магазине, реклама.

7. Использование в профессиональных целях землеустроителей, архитекторов, строителей и других, так как появляется возможность проведения измерений, оценки натурного состояния без выезда на объект. 
К недостаткам можно отнести:

1. Человеческий мозг все равно подсознательно понимает, что путешествие не является реальностью.

2. Емоции, память о событиях которые человек получает от реальных маршрутов, невозможно получить от виртуальных.

3. Требовательность к аппаратным ресурсам, стоимость программного обеспечения для создания виртуальных туров.

4. Необходимость периодического обновления туров для поддержания в актуальном состоянии.

Цель нашей работы заключается в том, чтобы создать виртуальный тур студгородка Национального университета водного хозяйства и природопользования, обеспечить студентов и преподавателей вуза визуализированным изображением территории университета. Для создания тура использована программа Kolor Panotour Pro, которая позволяет разработать с отдельных панорам виртуальный тур с интерактивными элементами, привязкой к карте, переходами между локациями, и тем самым помочь с поставленной целью.

Порядок создания тура наведен на рисунке 1.

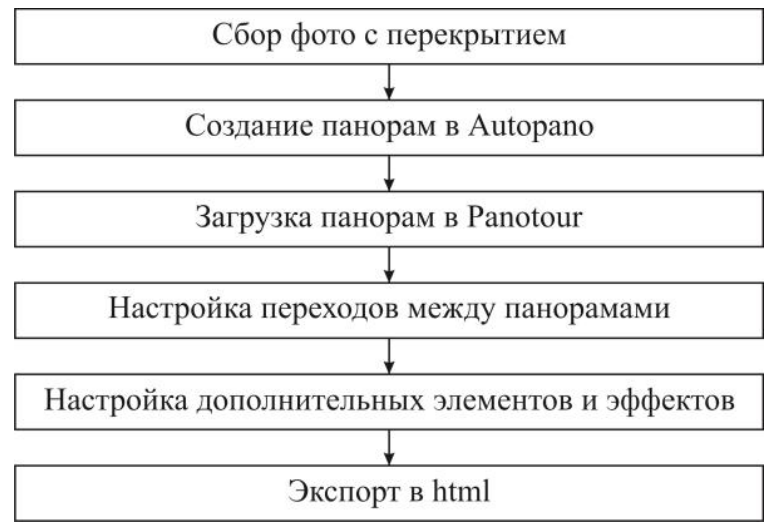

Рис. 1. Схема создания виртуального тура

Созданный виртуальный тур позволяет просматривать территорию студгородка и помочь в ориентировании абитуриентам и студентам (рис. 2). Перемещение в виртуальном пространстве происходит с помощью панели навигации. Можно запустить виртуальный тур на автозапуск, или каждую панораму на автовращение, просмотр в полноэкранном режиме. Добавлен план студгородка с размещением всех хотспотов и отображением текущего расположения и радара обзора. Этот же план можно использовать для быстрого перемещения в нужный хотспот. Для быстрого перехода на официальный сайт университета [11] или интерактивную карту [6] добавлены кнопки перехода в виде соответствующих эмблем. С помощью соответствующей кнопки панели навигации можно просмотреть 
информацию об авторах. К туру прикреплено музыкальное сопровождение. При необходимости возможно прикрепление и видеофрагментов.

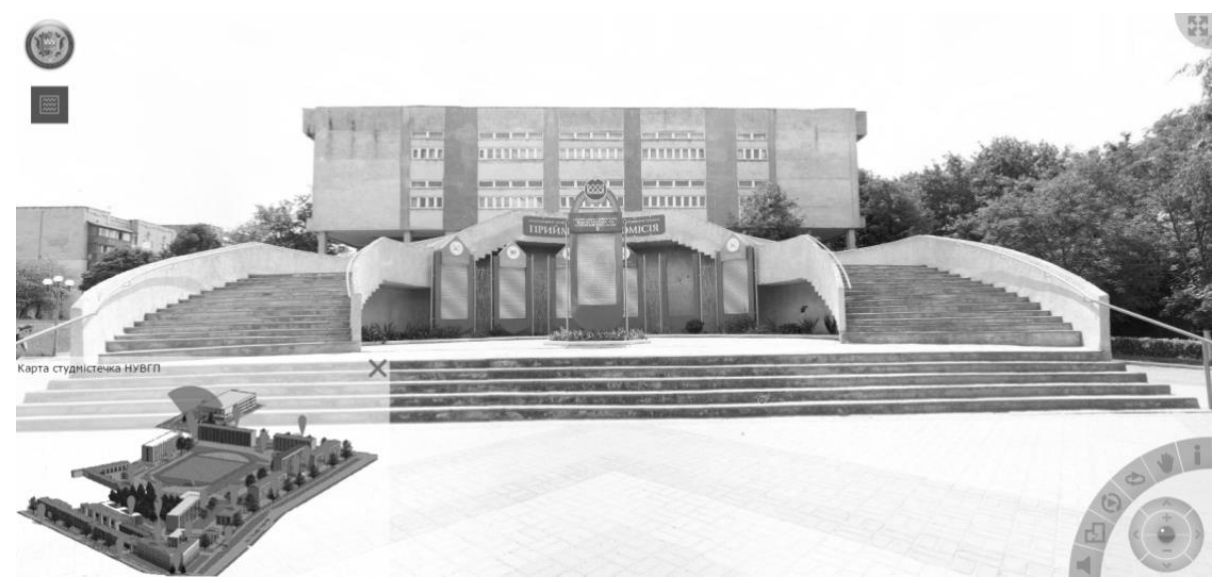

Рис. 2. Виртуальный тур студгородка НУвХП [3]

Для создания тура использовано 390 фотографий, которые объединены в 26 панорам. Каждая панорама состоит из 15 фотографий разрешением $3465 * 5202$.

В результате выполненой работы создан виртуальный тур студгородка, размещенный в сети Интернет на официальном сайте Национального университета водного хозяйства и природопользования [11] на вкладке Виртуальный студгородок [3]. Он предназначен не только для виртуальной "прогулки" во времени и пространстве, но и для ознакомления и изучения всех объектов территории университета. Его возможностями могут воспользоваться все желающие пользователи Интернет ресурсов, в первую очередь, абитуриенты, студенты и их родители. Путешествуя виртуальной реальностью, они могут сориентироваться в студгородке, почувствовать себя на месте осмотра, не выходя из квартиры.

\section{References}

[1] 3d туры [Электронный ресурс]. - Режим доступа: http://3dturov.net/3dtur/

[2] 3DSfera. Виртуальные туры [Электронный ресурс]. - Режим доступа: http://3dsfera.com.ua

[3] Віртуальне студмістечко НУВГП [Электронный ресурс]. - Режим доступа: http://go.nuwm.edu.ua/

[4] Віртуальний тур - Києво-Могилянська академія [Электронный ресурс]. - Режим доступа: http://www.ukma.edu.ua/index.php/kontakti/virtual-tour

[5] Віртуальний тур - Театр імені М. Заньковецької [Электронный ресурс]. - Peжим доступа: http://www.zankovetska.com.ua/about_the_theatre/virtual_tour/

[6] Інтерактивна карта студмістечка НУВГП [Электронный ресурс]. - Режим доступа: http://nuwm.edu.ua/map/index.html

[7] Карпаты ЗД [Электронный ресурс]. - Режим доступа: http://xn--37sbar0a5ags5f.com/uk/primenenie.html 
[8] Карты Google. Музей Соломон Гугенхайм [Электронный ресурс]. - Режим доступа: https://www.google.com/maps/place/

[9] Кузик 3., Іващенко С. Віртуальний тур як засіб документації об’єктів культурної спадщини // Сучасні досягнення геодезичної науки та виробництва. Львів, 2015. - Вип. 2 (30). - С. 82-86.

[10]Национальный музей «Чернобыль» Виртуальный тур [Электронный ресурс]. - Режим доступа: http://chornobylmuseum.kiev.ua/ru/ \%D0\%B2\%D0\%B8\%D1\%80\%D1\%82\%D1\%83\%D0\%B0\%D0\%BB\%D1\%8C\%D0 \%BD\%D1\%8B\%D0\%B9-\%D1\%82\%D1\%83\%D1\%80/5.

[11]Національний університет водного господарства та природокористування [Электронный ресурс]. - Режим доступа: http://nuwm.edu.ua

[12]Что такое виртуальный тур и виртуальная экскурсия, 3D тур? [Электронный peсурс]. - Режим доступа: https://www.pixiq.ru/virtual_tour 